\title{
Shifting to digital: informing the rapid development, deployment, and future of teaching and learning
}

\section{Introduction}

\author{
$\operatorname{Lin~Lin~}^{1} \cdot$ Tristan Johnson ${ }^{2}$ \\ Published online: 2 February 2021 \\ (c) Association for Educational Communications and Technology 2021
}

\section{The context}

Educational institutions and learning organizations with their teachers, professors, instructors, and students are quickly moving from physical classrooms to online settings due to the global COVID-19 pandemic. Although educational technology has been around for decades, the school administrators, teachers and technology staff are not prepared to address the rapid and dramatic needs to change and shift.

Educational Technology Research and Development (ETR\&D) is the flagship journal of the Association of Educational Communications and Technology (AECT). As editors of the journal, we saw the responsibility and opportunity to provide research-based and evidence-based resources for educational professionals to integrate digital technologies into their teaching practices. For over 65 years, ETR\&D has been publishing top-tier high-quality research and development studies that have explored different aspects of integrating digital technologies in educational settings. However, the published studies were conducted in different contexts and would not be directly applicable for teaching and learning in the rapidly changing pandemic situation. Meanwhile, we were also aware that time is of essence, and that we would not have the time required to solicit new research studies to address the current needs, because it would take time for scholars to conduct such research, and it would take time for new submissions to go through a double-blind peer review process.

All things considered, we proposed a unique special issue idea to our ETR\&D editorial board members. The idea was to call for commentary or essay-style papers that would situate ETR\&D recently published research studies in the current pandemic situation, draw insights from the publications, and provide recommendations for teaching and learning

Lin Lin

Lin.Lin@unt.edu

Tristan Johnson

tristan.johnson@bc.edu

1 Department of Learning Technologies, Texas Center for Educational Technology, University of North Texas, 3940 North Elm Street, Discovery Park G150, Denton, TX 76207, USA

2 Woods College of Advancing Studies-Boston College, Haley House, 314 Hammond Street, Chestnut Hill, MA 02467, USA 
during these rapid shifts. The editorial board members not only supported the proposal unanimously, but also offered their time and expertise as guest editors to move this special issue swiftly forward. The core guest editors of the special issue included Drs. Dickson-Deane, Ilgaz, Ioannou, Kimmons, Morel, Natividad, Istenič Starčič, Wijekumar, and Young (in the alphabetical order of guest editors' last names). The guest editors communicated with the potential authors and reviewers, and ensured the quality of the submissions. Dr. Istenič Starčič kindly offered to be the lead guest editor to help streamline the papers for the special issue in the editorial manager system. Drs. Johnson, Spector, and Lin participated in the discussions, and coordinated the editorial process.

Therefore, with this special issue-Shifting to Digital, we sought to provide insights into the applications of relevant research informing the rapid development, deployment and future of teaching and learning. We also deliberately sought to include multiple perspectives by seeking authors with varying professional experiences, from diverse nationalities representing a global perspective inclusive of the challenge.

\section{The process}

Over numerous meetings, the guest editors identified 17 papers published at ETR\&D in the past five years, and selected these 17 papers to be responded in this special issue. Criteria for selecting these papers included their relevance to online or digital learning, relevance to rapid deployment, impact factor, scope, and appeal to a wide and diverse population. The goal, however, was not to select a set of best papers by any means, but to use the papers as anchors for creating dialogue and proving useful suggestions for practices towards future research.

To accelerate the process and to balance the workload, every guest editor chose one or two of the 17 selected papers and oversaw the review processes of the corresponding essays to these papers. Table 1 below lists the key guest editors (in the alphabetical order

Table 1 Guest editors and the selected manuscripts for responses

\begin{tabular}{|c|c|}
\hline Guest editors & Manuscripts responded by essays in this special issue \\
\hline $\begin{array}{l}\text { Camille Dickson-Deane, University of Technology } \\
\text { Sydney, Australia }\end{array}$ & Bennett et al. (2017) and Zacharia et al. (2015) \\
\hline Hale Ilgaz, Ankara University, Ankara, Turkey & Joo et al. (2016) and Nacu et al. (2018) \\
\hline $\begin{array}{l}\text { Andri Ioannou, Cyprus University of Technology } \\
\text { (Cyprus), Cyprus }\end{array}$ & Giannakas et al. (2018) and Ke (2016) \\
\hline Royce Kimmons, Brigham Young University, USA & Hilton (2016) and Ifenthaler and Schumacher (2016) \\
\hline Gwen Morel, Texas State University, USA & $\begin{array}{l}\text { Lee and Hannafin (2016) and Tracey and Hutchinson } \\
\text { (2019) }\end{array}$ \\
\hline $\begin{array}{l}\text { Gloria Natividad, Technological Institute of Saltillo, } \\
\text { Saltillo, Mexico }\end{array}$ & $\begin{array}{l}\text { Philipsen et al. (2019) } \\
\text { Willis et al. (2016) }\end{array}$ \\
\hline $\begin{array}{l}\text { Andreja Istenič Starčič, University of Ljubljana, } \\
\text { Slovenia }\end{array}$ & $\begin{array}{l}\text { Borup et al. (2015) } \\
\text { Kuo and Belland (2016) }\end{array}$ \\
\hline Kausalai Wijekumar, Texas A\&M University, USA & Jarrell et al. (2017) \\
\hline $\begin{array}{l}\text { Patricia Young, University of Maryland Baltimore } \\
\text { County, USA }\end{array}$ & Liu et al. (2019) and Loizzo and Ertmer (2016) \\
\hline
\end{tabular}


of the last names of the guest editors), and the manuscripts they oversaw for selecting corresponding essays in the review process.

We created a call for papers for the "Special Issue - Shifting to Digital". The special issue called for essay-style response papers (500-1000 words) to the 17 selected publications via AECT newsletter, listserv, websites, and social media. In addition, guest editors reached out to various networks to share the call for papers. The responding essays would address the selected papers by people with varying backgrounds, cultures, expertise, and experiences. The goal was to seek multiple perspectives, which would include, but would not be limited to: theory, research, design, practices, ethics, policy, culture.

\section{Review criteria}

We established several review criteria for the essay-style responses situating the 17 previously published articles within the current learning needs of the COVID-19 pandemic. We first defined what we meant by "Shifting to Digital". We asked that the potential respondent authors provide useful ideas for flexible learning, online learning, learning disruptions, especially where limited resources would be available, or situations where one would have to pivot to different teaching and learning methods within a shortened period of time. We asked that the responding authors focus their commentary pieces on the following aspects:

- Impact/Value-What impact or value does the paper have on "Shift to Digital" from your specific perspective? What ideas from this paper contribute to its value?

- Application-What information from your manuscript can be used to make the "Shift to Digital"? Given your specific perspective, how do you take ideas presented in the manuscript and use them (i.e., providing specific context and audience)?

- Limitations and Constraints-What limitations and constraints do you have about the paper as it relates to your selected perspective?

- Future Suggestions-What constructive suggestions do you have for future work, related to your perspective and the ideas presented in the selected manuscript?

The potential responding authors were asked to identify 2-3 manuscripts for which they were interested in authoring a response, and to specify the perspective on which they would focus in their response paper. The authors were then invited by the guest editors to write one essay response with the understanding that their submission would go through a double-blind peer-review, and that the invitation to author the response would not guarantee the article's acceptance or publication in ETR\&D.

Additionally, the guest editors agreed that only one first-authored or single-authored paper from each scholar would be included in this special issue. Again, the goal was to include multiple and diverse voices. All submissions went through a double-blind peer review process, with a range of one to four rounds of revisions.

Finally, we accepted approximately 80 response essays for this special issue. These essays each brought unique perspectives to help bridge the research-based and evidencebased publications with a need to better inform the rapid deployment, development, and future of teaching and learning. The guest editors each also provided a summary of the accepted papers responding to the publications they oversaw. Drs. Spector and Harris were invited to write a conclusion piece for this special issue. 


\section{Multiple perspectives}

Given the challenges of Shifting to Digital, we made it a top priority to seek multiple response essays to each of the 17 selected publications, with each essay focusing on a primary perspective. It was important for us to encourage diverse perspectives to provide contextual differences while informing practices. This special issue includes close to a hundred essays in total, with authors from different sectors and included discussions for K12, non-profit, profit, and higher education settings. The authors wrote from perspectives including, for instance, Adoption \& Diffusion, Context \& Environments, Critical Pedagogy, Culture \& Equity, Design, Ethics, Evaluation, Inclusion, Pedagogy, Policy, Practice, Research, Theory, and International Perspective.

\section{Conclusion}

This special issue was created to inform the processes and challenges of rapid digital development, deployment, and to provide insights into the future of teaching and learning. As editors, we consider it critical, not only to ensure the quality of published scholarship through a double-blind peer-review process, but also to seek ways to connect these works to our readership and to the consumers of knowledge. With the work of all those who contributed to this special issue, we feel that we can start to address the need to share the abundance of evidence-based research and development that have been conducted and published by the interdisciplinary community of scholars in learning technologies, learning sciences, instructional design, and educational technology practices. With this evolving monumental task during the past eight months, the entire special issue team aimed to create dialogues, stimulate reflection, and inform best practices. Now we welcome your comments and feedback for ways to continue this dialogue about the implications of research and knowledge in our world of teaching and learning.

\section{References}

Bennett, S., Agostinho, S., \& Lockyer, L. (2017). The process of designing for learning: Understanding university teachers' design work. Educational Technology Research and Development, 65, 125145. https://doi.org/10.1007/s11423-016-9469-y.

Borup, J., West, R. E., \& Thomas, R. (2015). The impact of text versus video communication on instructor feedback in blended courses. Educational Technology Research and Development, 63, 161-184. https://doi.org/10.1007/s11423-015-9367-8.

Giannakas, F., Kambourakis, G., Papasalouros, A., et al. (2018). A critical review of 13 years of mobile game-based learning. Educational Technology Research and Development, 66, 341-384. https:// doi.org/10.1007/s11423-017-9552-z.

Joo, Y. J., Kim, N., \& Kim, N. H. (2016). Factors predicting online university students' use of a mobile learning management system (m-LMS). Educational Technology Research and Development, 64, 611-630. https://doi.org/10.1007/s11423-016-9436.

Ke, F. (2016). Designing and integrating purposeful learning in game play: A systematic review. Educational Technology Research and Development, 64, 219-244. https://doi.org/10.1007/s1142 3-015-9418-1. 
Kuo, Y., \& Belland, B. R. (2016). An exploratory study of adult learners' perceptions of online learning: Minority students in continuing education. Educational Technology Research and Development, 64, 661-680. https://doi.org/10.1007/s11423-016-9442-9.

Hilton, J. (2016). Open educational resources and college textbook choices: A review of research on efficacy and perceptions. Educational Technology Research and Development, 64, 573-590. https://doi. org/10.1007/s11423-016-9434-9.

Ifenthaler, D., \& Schumacher, C. (2016). Student perceptions of privacy principles for learning analytics. Educational Technology Research and Development, 64, 923-938. https://doi.org/10.1007/s1142 3-016-9477-y.

Jarrell, A., Harley, J. M., Lajoie, S., et al. (2017). Success, failure and emotions: Examining the relationship between performance feedback and emotions in diagnostic reasoning. Educational Technology Research and Development, 65, 1263-1284. https://doi.org/10.1007/s11423-017-9521-6.

Lee, E., \& Hannafin, M. J. (2016). A design framework for enhancing engagement in student-centered learning: Own it, learn it, and share it. Educational Technology Research and Development, 64, 707-734. https://doi.org/10.1007/s11423-015-9422-5.

Liu, J., Shindo, H., \& Matsumoto, Y. (2019). Development of a computer-assisted Japanese functional expression learning system for Chinese-speaking learners. Educational Technology Research and Development, 67, 1307-1331. https://doi.org/10.1007/s11423-019-09669-0.

Loizzo, J., \& Ertmer, P. A. (2016). MOOCocracy: The learning culture of massive open online courses. Educational Technology Research and Development, 64, 1013-1032. https://doi.org/10.1007/s1142 3-016-9444-7.

Nacu, D., Martin, C. K., \& Pinkard, N. (2018). Designing for 21st century learning online: A heuristic method to enable educator learning support roles. Educational Technology Research and Development, 66, 1029-1049. https://doi.org/10.1007/s11423-018-9603-0.

Philipsen, B., Tondeur, J., Pareja Roblin, N., et al. (2019). Improving teacher professional development for online and blended learning: A systematic meta-aggregative review. Educational Technology Research and Development, 67, 1145-1174. https://doi.org/10.1007/s11423-019-09645-8.

Tracey, M. W., \& Hutchinson, A. (2019). Empathic design: Imagining the cognitive and emotional learner experience. Educational Technology Research and Development, 67, 1259-1272. https://doi. org/10.1007/s11423-019-09683-2.

Willis, J. E., Slade, S., \& Prinsloo, P. (2016). Ethical oversight of student data in learning analytics: A typology derived from a cross-continental, cross-institutional perspective. Educational Technology Research and Development, 64, 881-901. https://doi.org/10.1007/s11423-016-9463-4.

Zacharia, Z. C., Manoli, C., Xenofontos, N., et al. (2015). Identifying potential types of guidance for supporting student inquiry when using virtual and remote labs in science: A literature review. Educational Technology Research and Development, 63, 257-302. https://doi.org/10.1007/s11423-015-9370-0.

Publisher's Note Springer Nature remains neutral with regard to jurisdictional claims in published maps and institutional affiliations.

Dr. Lin Lin is Professor of Learning Technologies at the University of North Texas. Her research looks into intersections of mind, brain, technology and learning. She also serves as the Director for the Texas Center for Educational Technology (TCET), and as the Development Editor-in-Chief ETR\&D.

Dr. Tristan Johnson is Associate Dean for Graduate Programs of the Woods College of Advancing Studies at the Boston College. His expertise lies in building online and on-ground academic programs, strengthening curriculum quality, and enhancing industry alignment. He serves as the Research Editor-in-Chief for ETR\&D. 